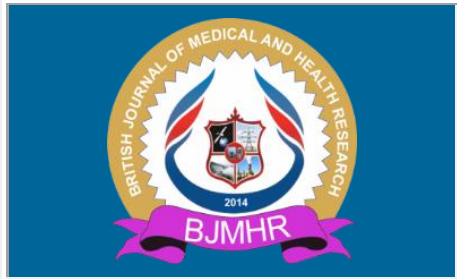

\title{
BJMHR
}

British Journal of Medical and Health Research

Journal home page: www.bjmhr.com

\section{Correlation between Serum Uric acid In Pre Diabetics and Diabetics: A Prospective Observational Study}

\section{Anubhav Gupta*1, Jagrati Gupta ${ }^{2}$, Snehal .T. Sanghavi ${ }^{3}$ \\ 1. Post Graduate Department of Medicine, Saifee Hospital, Mumbai, Maharashtra}

2. Post Graduate Department of Family Medicine, Saifee Hospital, Mumbai,Maharashtra

2. Senior Faculty Member in Department of Medicine, Saifee Hospital, Mumbai, Maharashtra

\section{ABSTRACT}

To determine the level of serum uric acid level in diabetics and pre diabetics individuals. To compare the level of serum uric acid, FPG , HBA1C in pre diabetics and diabetics. There was a significant relation between prediabetics who were younger in age compared to diabetics (almost a decade younger). The gender distribution was identical between the two groups. 53\% had complaint <1 year.39\% had isolated HTN; 9\% had IHD whereas 19\% had both. The diabetics had HbA1c significantly higher than prediabetics. Although proportionately more prediabetics had raised creatinine levels, but the difference was not significant. The difference of mean uric acid wrt HbA1c was not significant, although people with lower HbA1c values had a higher uric acid levels. The difference was not significant wrt uric acid levels with FBS values in prediabetics. The difference was not significant, although people with lower PPBS had higher uric acid levels in prediabetics. There was a significant relation of lower uric acid mean values for people with elevated $\mathrm{HbA1c}$ over $7 \mathrm{~g} \%$ amongst diabetics. There was no significant relation, although mean uric acid levels were raised for people with FBS $<110$ amongst diabetics. There was no significant relation but uric acid levels were higher in people with PPBS <140 amongst diabetics Younger age in India is predisposed to prediabetes and diabetes. Often patients are silent, without symptoms and detected only by investigations, so investigations for prediabetes and diabetes should be mandatorily routine. Lower uric acid levels have correlation with impaired glycemic control and should be part of check ups for metabolic syndromes. Hypertension and heart disease commonly coexist with diabetes and should be tackled together. Uric acid monitoring should have a role in guiding glycemic goals.

Keywords: Serum uric acid, FBS, PPBS , Pre diabetics , Diabetics 


\section{INTRODUCTION}

Diabetes mellitus is a heterogeneous group of metabolic disorders characterized by chronic hyperglycemia with disturbance of carbohydrate, fat and protein metabolism resulting from defects in insulin secretion, insulin action or both. ${ }^{1}$ It is considered a disorder of ageing, but can affect any age group. The effect of diabetes mellitus includes long term damage, dysfunction and failure of various organs, eyes, kidneys, nerves and heart, and blood vessels The vast majority of cases of diabetes fall into two broad etiopathogenetic categories - those having little or no endogenous insulin secretory capacity (IDDM or type 1 diabetes mellitus) and those who retain endogenous insulin secretory capacity but have a combination of resistance to insulin action and an inadequate compensatory insulin secretory response (NIDDM or type 2 diabetes mellitus). ${ }^{2}$ Both the diseases are widely prevalent across the globe and adding to morbidity and mortality.

Without concerted action to prevent diabetes, in less than 25 years' time there will be 592 million people living with the disease. ${ }^{3}$ Most of those cases would be preventable with lifestyle changes, dietary habits and health education i.e. primordial and primary prevention. In the year 2013, there were 382 million people living with diabetes. ${ }^{4}$ By the end 2013, diabetes had caused 5.1 million deaths. ${ }^{5}$ Type 2 diabetes accounts for approximately 90 to $95 \%$ of all diagnosed cases of diabetes. ${ }^{6}$ Studies suggest that at the time of diagnosis, the typical patient with type 2 diabetes mellitus have diabetes for at least 4 to 7 years. $^{7}$

Among patients with type 2 diabetes mellitus, 25\% are believed to have retinopathy, 9\% nephropathy and $8 \%$ neuropathy at the time of diagnosis. ${ }^{8}$ Often the presenting symptoms of Type 2 diabetes may be the end organ complication, and diabetes detected subsequently on investigation for this end organ complication.

Micronutrients have been investigated as potential, preventive and therapeutic agents for type 2 diabetes mellitus and their complications. In particular, diabetes has shown to be associated with abnormalities in the metabolism of zinc, chromium, copper, magnesium and manganese. ${ }^{9}$

IFG is defined as FPG levels between 100 and $125 \mathrm{mg} / \mathrm{dL}$ (between 5.6 and $6.9 \mathrm{mmol} / \mathrm{L}$ ) (24, 25) and IGT as 2-h PG during 75-g OGTT levels between 140 and $199 \mathrm{mg} / \mathrm{dL}$ (between 7.8 and $11.0 \mathrm{mmol} / \mathrm{L})^{10}$. It should be noted that the World Health Organization (WHO) and numerous other diabetes organizations define the IFG cutoff at $110 \mathrm{mg} / \mathrm{dL}(6.1 \mathrm{mmol} / \mathrm{L}) .{ }^{10}$ Uric acid is formed by the breakdown of purines and by direct synthesis from 5phosphoribosyl pyrophosphate and glutamine. ${ }^{11}$ Serum urate levels vary with age and sex. Most children have serum urate concentrations of 180 to $240 \mu \mathrm{mol} / 1$ (3.0 to $4.0 \mathrm{mg} / \mathrm{dl})$. ${ }^{12}$ Levels begin to rise in males during puberty but remain low in females until menopause. 
Mean serum urate values of adult men and premenopausal women are 415 and $360 \mu \mathrm{mol} / \mathrm{L}$ $(6.8$ and $6.0 \mathrm{mg} / \mathrm{dl})$, respectively. After menopause, values for women increase to approximate those of men. In adulthood, concentrations rise steadily over time and vary with height, body weight, blood pressure, renal function, and alcohol intake .Several epidemiological studies have reported that high serum levels of uric acid are strongly associated with prevalent health conditions such as obesity, insulin resistance, metabolic syndrome, diabetes, essential hypertension, and renal disease. Population- based studies have shown that hyperuricemia is an independent risk factor for cardiovascular disease (CVD). This association has been found to be particularly robust among individuals at high risk for CVD, including those with obesity, hypertension, diabetes and renal disease. With the above background, this study was done to examine the serum level of uric acid in diabetics and prediabetics.

\section{Lacunae in Existing Literature}

On meticulous review of published literature wrt hyperuricemia and dysglycemia, it is seen that there is no Indian study observing this correlation, and existing studies have conflicting outcomes with no uniform consensus.

\section{RATIONALE OF THIS STUDY \& DEFINING THE RESEARCH QUESTION}

The research question stands as is there any relation in Indian population between hyperuricemia and dysglycemia? This study aims to address this question in Indian population derived from Mumbai and allied areas.

\section{Aims and Objectives}

1) To determine the level of serum uric acid level in diabetics and pre diabetics individuals.

2) To compare the level of serum uric acid, FPG, HBA1C in pre diabetics and diabetics.

\section{MATERIALS AND METHOD}

\section{Study Design}

A single Centre, hospital based prospective observational study.

\section{Study site}

Department of Medicine, Saifee Hospital, Mumbai including both Indoor, OPD and emergency

\section{STUDY PERIOD}

\section{JANUARY 2019- JANUARY2020}

\section{Study subjects}

50 pre diabetics and 50 diabetics, admitted or visiting OPD in Department of Medicine, Saifee Hospital, Mumbai. 


\section{Inclusion criteria}

1. Patients with Diabetes Mellitus (ADA criteria for diabetes)

2. Pre-diabetes (Impaired Fasting Glucose/Impaired Postprandial Glucose)

3. Non diabetics.

4. All age groups \& both sexes.

\section{Exclusion criteria}

1. Patients with serum creatinine $>1.3 \mathrm{mg} / \mathrm{dl}$

2. Subjects with any diagnosed malignancy.

3. Individuals diagnosed as suffering from gout.

4. Patients on drugs which alters serum uric acid levels.(diuretics, levodopa, Pyrazinamide.)

5. All other conditions which increase or decrease serum uric acid levels

\section{SAMPLE SIZE CALCULATION}

The sample size for observational studies is given as

$\mathrm{N}=\mathrm{Zp}(1-\mathrm{p}) / \mathrm{d}^{2}$

Where $\mathrm{N}=$ sample size

$$
\begin{aligned}
& \mathrm{Z}=1.96 \\
& \mathrm{p}=\text { maximum expected prevalence }=0.5 \\
& \mathrm{~d}=\text { acceptable error }=10 \%
\end{aligned}
$$

From simple calculation, sample size $=100$

There were 50 subjects in each group i.e. pre diabetic and diabetic

\section{Sampling method-}

Every consecutive patient fulfilling diagnostic criteria and inclusion and exclusion criteria, giving informed and written consent were enrolled to complete the sample size in the stipulated duration ie convenience sampling.

\section{Method of collection of data}

This was hospital based observational study involving 100 patients (50 each in each group). Detailed history was taken including duration of diabetes, treatment mode, followed by physical examination. Postprandial blood sugar was measured two hours after a standard meal.

Hexokinase/G6PDH enzymatic method for measuring blood glucose as per American Diabetes Association, 2017. Fasting blood glucose of $<100 \mathrm{mg} / \mathrm{dL}$ was taken as normal glucose tolerance, $100-125 \mathrm{mg} / \mathrm{dL}$ as impaired glucose tolerance and $>126 \mathrm{mg} / \mathrm{dL}$ as abnormal glucose tolerance. Postprandial blood sugar of $<140 \mathrm{mg} / \mathrm{dL}$ was taken as normal glucose tolerance, $140-199 \mathrm{mg} / \mathrm{dL}$ as impaired glucose tolerance and $>200 \mathrm{mg} / \mathrm{dL}$ as 
abnormal glucose tolerance. HbA1c estimation was done by enzymatic method measuring $\mathrm{N}$-terminal fructosyl dipeptides of the $\beta$ peptide chain.

\section{Statistical Analysis}

The data was entered into Microsoft excel data sheet and analyzed using SPSS software. Categorical data has been represented in the form of frequencies and proportions. Chi-square test has been used as test of significance. Continuous data has been represented as mean and standard deviation. Independent t-test has been used as test of significance to identity the mean difference between two groups, p-value $<0.05$ considered as statistically significant.

\section{RESULTS AND DISCUSSION}

This study was performed in department of medicine, Saifee hospital Mumbai, where patients who were pre diabetics and diabetics were selected as per inclusion and exclusion criteria and the following findings were observed

Table 1: for age distribution

\begin{tabular}{llll}
\hline & Pre-diabetes & Diabetes & P value \\
\hline$<50 \mathrm{yrs}$ & 29 & 18 & 0.045 \\
$>=50 \mathrm{yrs}$ & 21 & 32 & \\
Mean +- SD & $47.7+-12.09$ & $55.92+-12.99$ & 0.002 \\
\hline
\end{tabular}

There was a significant relation between prediabetics who were younger in age compared to diabetics (almost a decade younger)

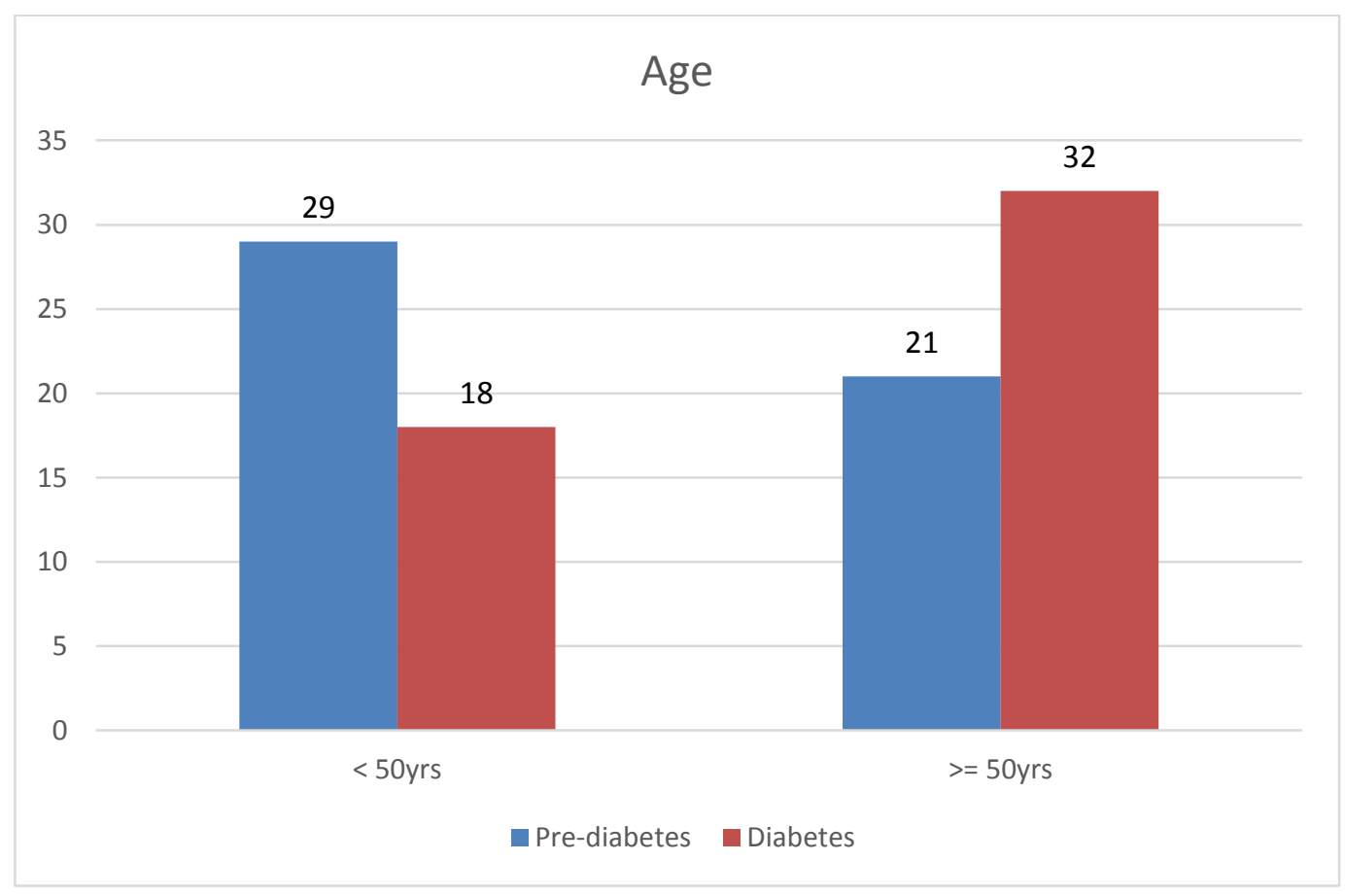

Figure 1: Bar diagram

Table 2: For gender distribution

\begin{tabular}{llll}
\hline & Pre-diabetes & Diabetes & P value \\
\hline Male & 31 & 32 & 1 \\
Female & 19 & 18 & \\
\hline
\end{tabular}

The gender distribution was identical between the two groups 


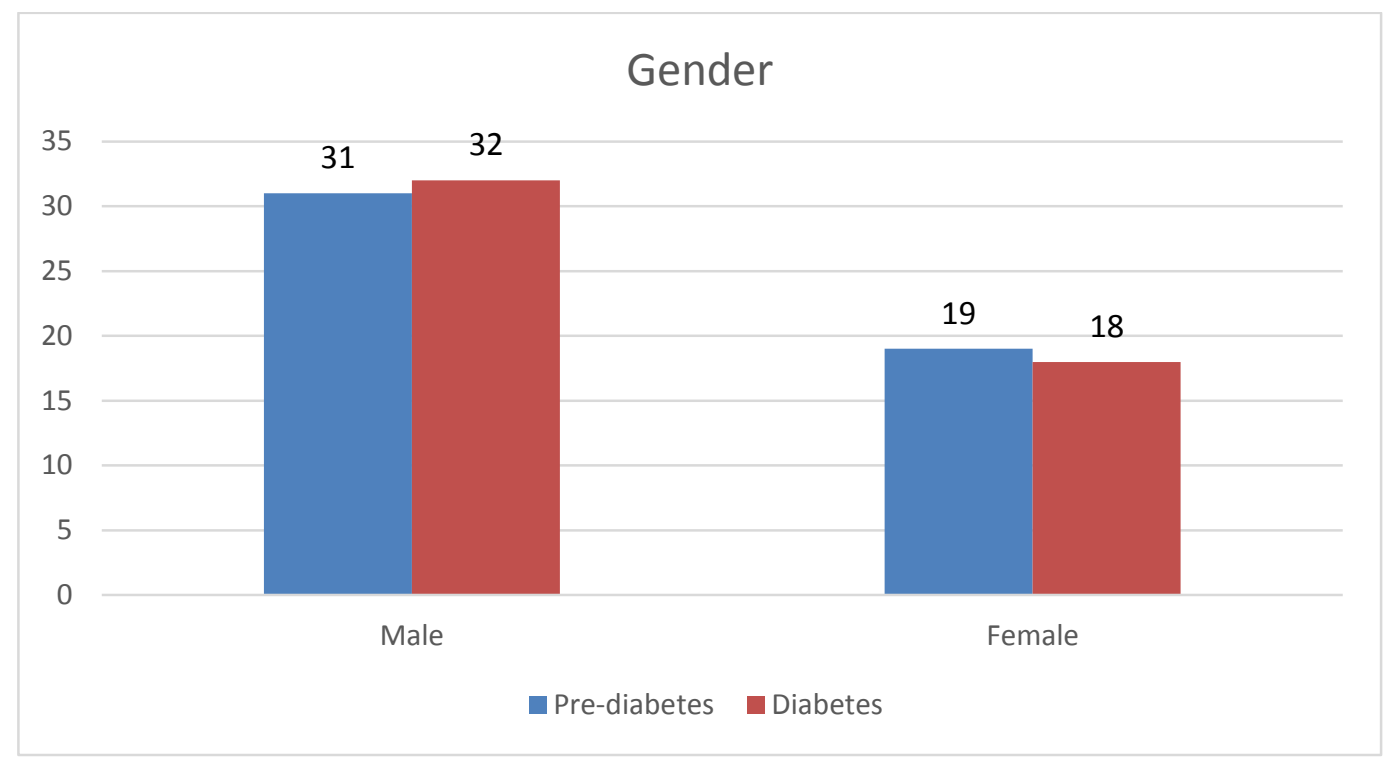

Figure 2: Bar diagram

Table 3: Table for duration of complaints

\begin{tabular}{lll}
\hline & Number of patients & Percent \\
\hline$<1 \mathrm{yr}$ & 53 & 53 \\
$>=1 \mathrm{yr}$ & 47 & 47 \\
Total & 100 & 100
\end{tabular}

$53 \%$ had complaint $<1$ year

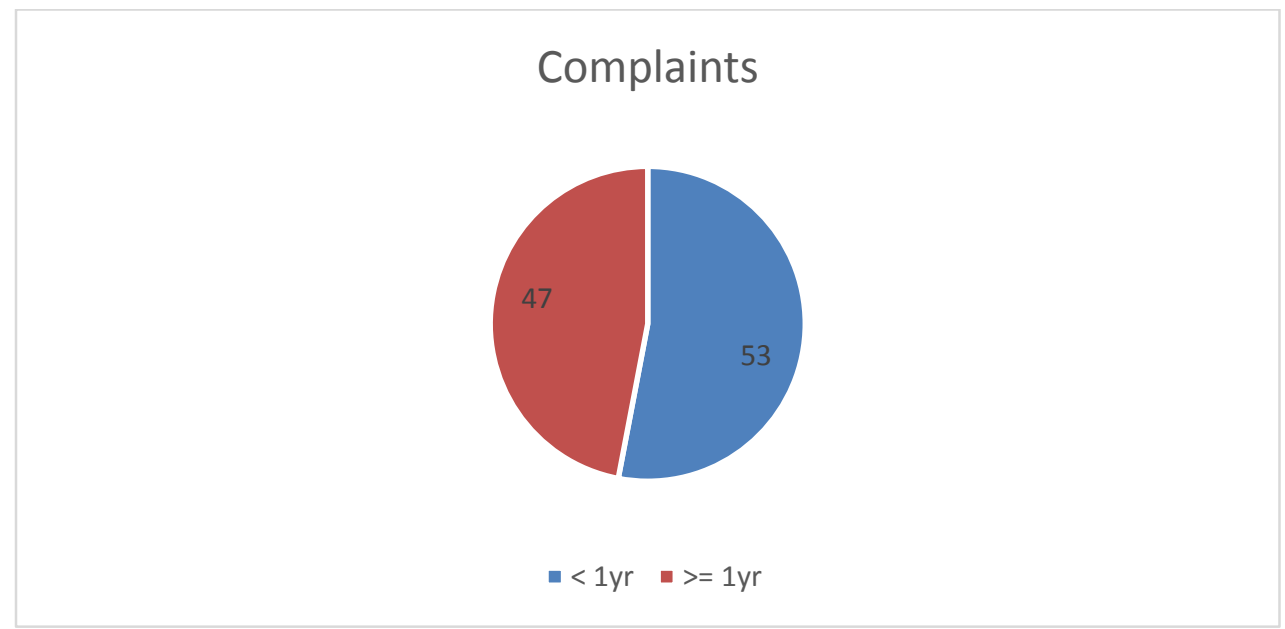

Figure 3: Pie chart

Table 4 : Table for type of treatment

\begin{tabular}{lll}
\hline & Number of patients & Percent \\
\hline None & 7 & 7 \\
Insulin toha & 44 & 44 \\
Oha & 49 & 49 \\
Total & 100 & 100 \\
\hline
\end{tabular}

$49 \%$ were on only OHAs, whereas $44 \%$ received both Insulin and OHAs. $7 \%$ did not receive any medicines for diabetes prior to this study. 


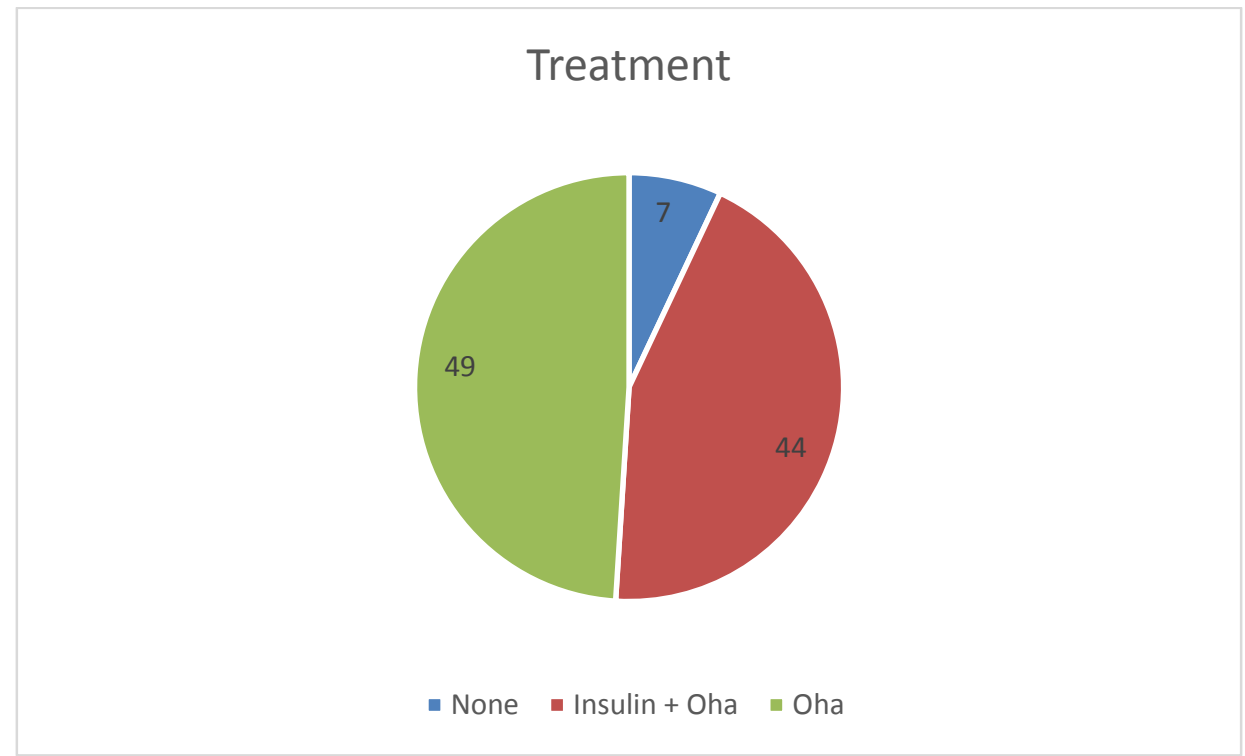

Figure 4: Pie chart

Table 5: Table for comorbidities

\begin{tabular}{lll}
\hline & Number of patients & Percent \\
\hline HTN & 39 & 39 \\
IHD & 9 & 9 \\
Both & 19 & 19 \\
None & 33 & 33 \\
Total & 100 & 100 \\
\hline
\end{tabular}

$39 \%$ had isolated HTN; $9 \%$ had IHD whereas $19 \%$ had both. $33 \%$ did not have any comorbidity.

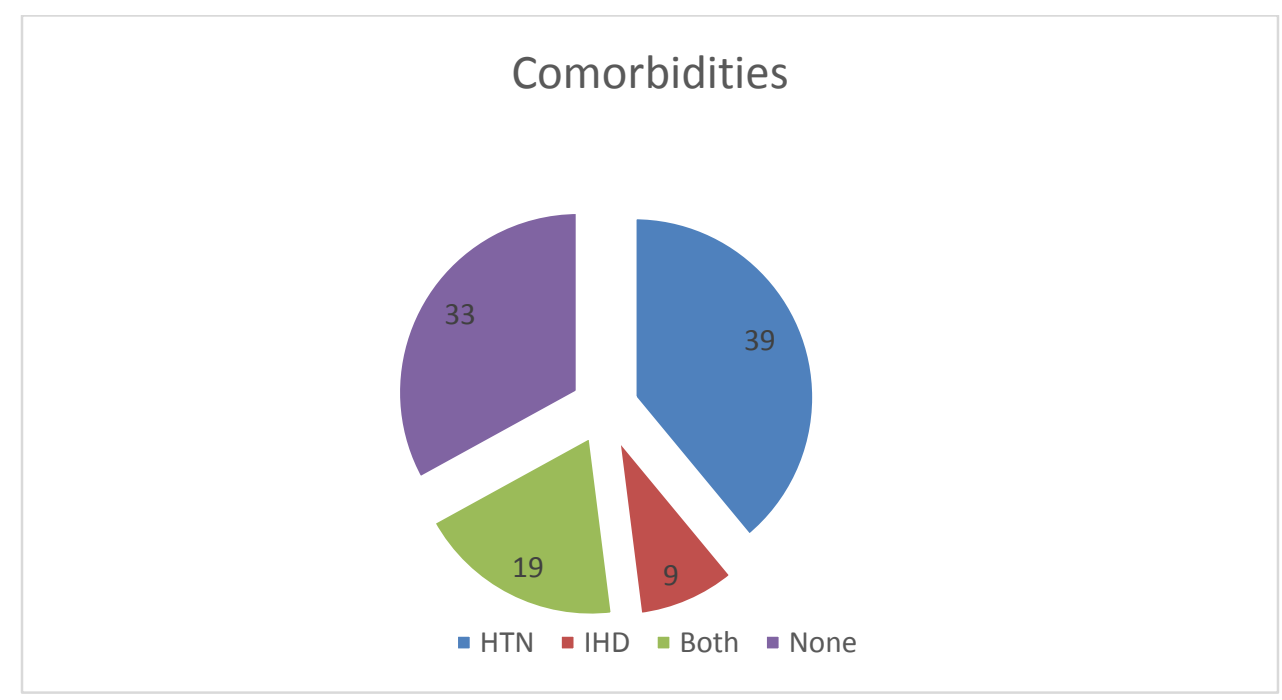

Figure 5: Pie chart

Table 5: Relation between FBS between pre-diabetics and diabetics

\begin{tabular}{llll}
\hline & Pre-diabetes & Diabetes & P value \\
\hline$<110$ & 38 & 8 & 0.00001 \\
$110-126$ & 8 & 11 & 0.61 \\
$>126$ & 4 & 31 & 0.00001 \\
Mean+- SD & $106.6+-20.41$ & $154.56+-48.41$ & 0.0001 \\
\hline
\end{tabular}

There was a significant relation of FBS $<110$ in prediabetics compared to diabetics $>126$ 


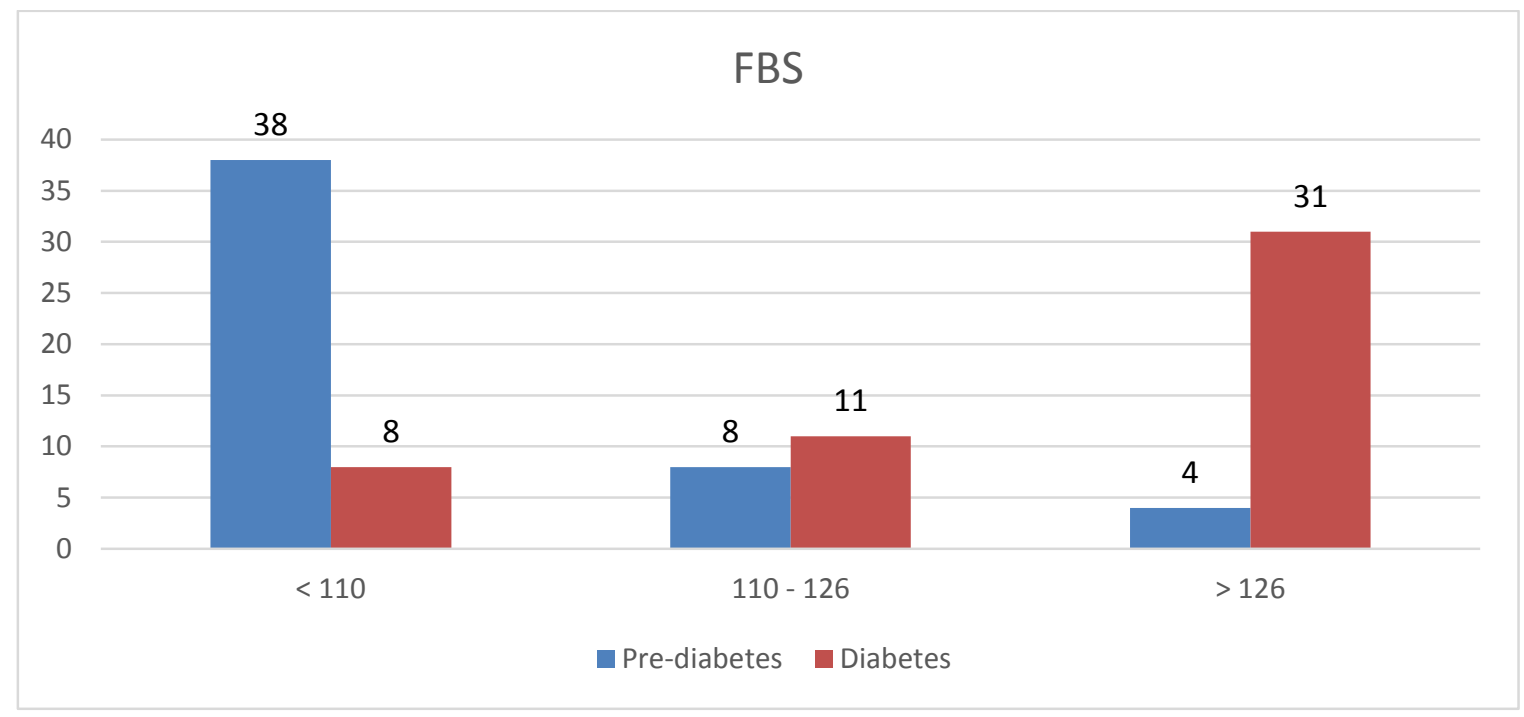

Figure 6: Bar diagram

Table 6: Relation between PPBS between pre-diabetics and diabetics

\begin{tabular}{llll}
\hline & Pre-diabetes & Diabetes & P value \\
\hline$<140$ & 39 & 8 & 0.00001 \\
$140-200$ & 9 & 19 & 0.045 \\
$>200$ & 2 & 23 & 0.00001 \\
Mean+- SD & $113.14+-33$ & $216.86+-83.57$ & 0.0001 \\
\hline
\end{tabular}

There was a significant relation of PPBS $<140$ between prediabetics compared to diabetics $>200$

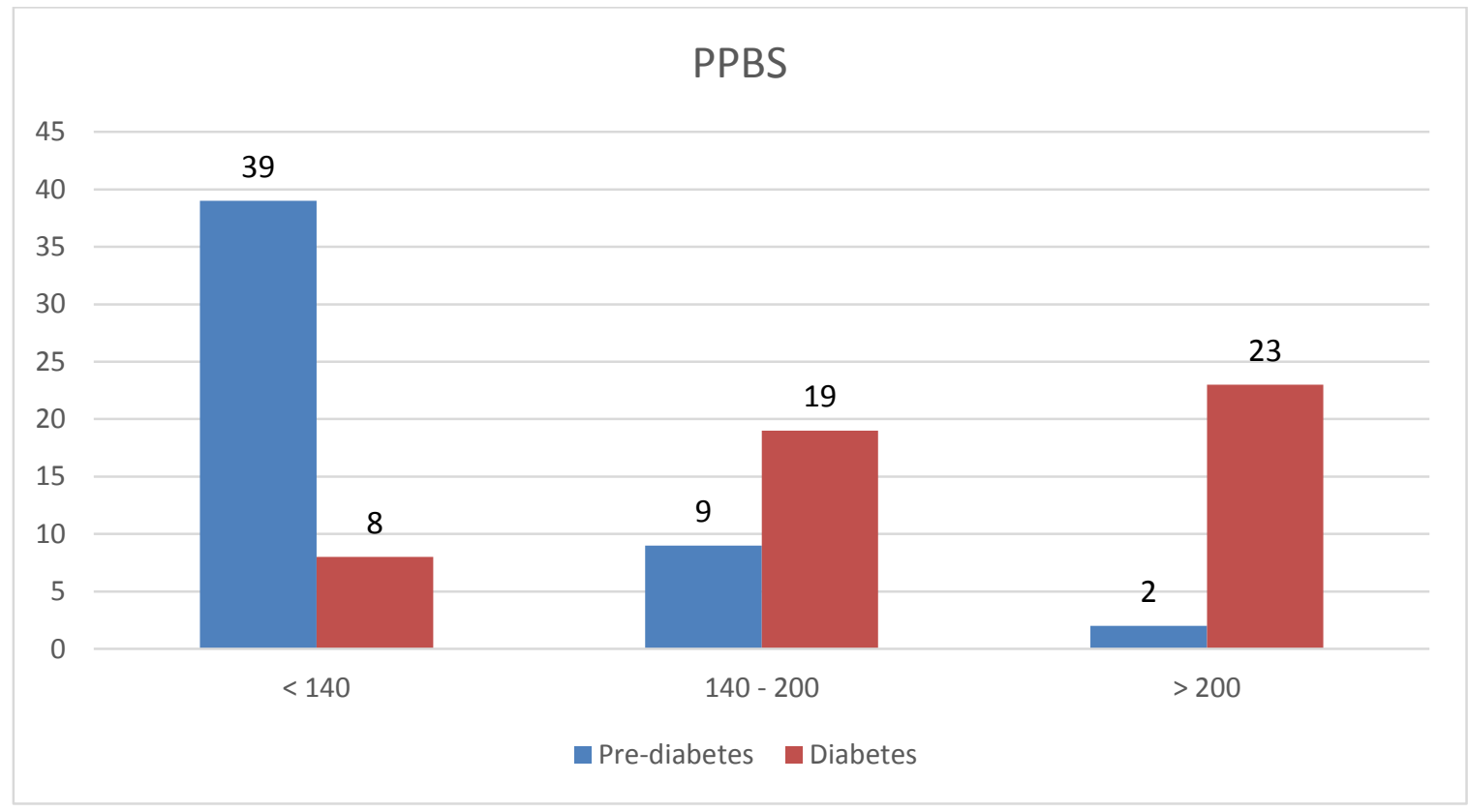

Figure 7: Bar diagram

Table 7: Relation of HbA1c between pre-diabetics and diabetics

\begin{tabular}{llll}
\hline & Pre-diabetes & Diabetes & P value \\
\hline HbA1c $<6.4$ & 46 & 0 & NA \\
HbA1c $>=6.4$ & 4 & 50 & \\
Mean+-SD & $5.96+-0.223$ & $8.52+-2.11$ & $<0.0001$ \\
\hline
\end{tabular}

The diabetics had HbA1c significantly higher than prediabetics. 


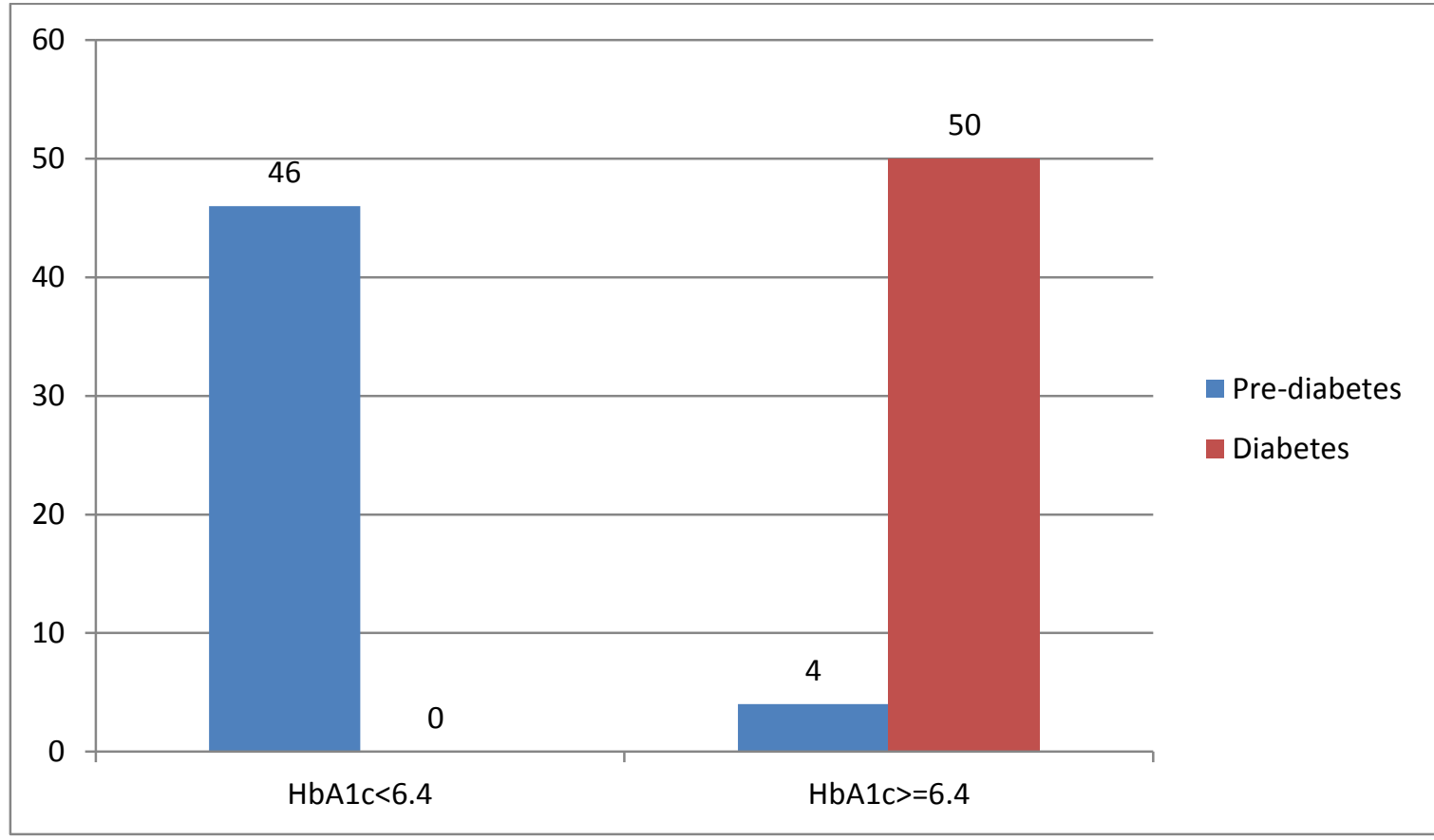

Figure 8: Bar diagram

Table 8: Relation of uric acid between pre-diabetics and diabetics

\begin{tabular}{llll}
\hline & Pre-diabetes & Diabetes & P value \\
\hline Normal (male $<7 ;$ female $<6)$ & 36 & 40 & 0.482 \\
Raised & 14 & 10 & \\
Mean+- SD & $6.04+-1.37$ & $5.56+-1.79$ & 0.135 \\
\hline
\end{tabular}

Although proportionately more prediabetics had raised creatinine levels, but the difference was not significant.

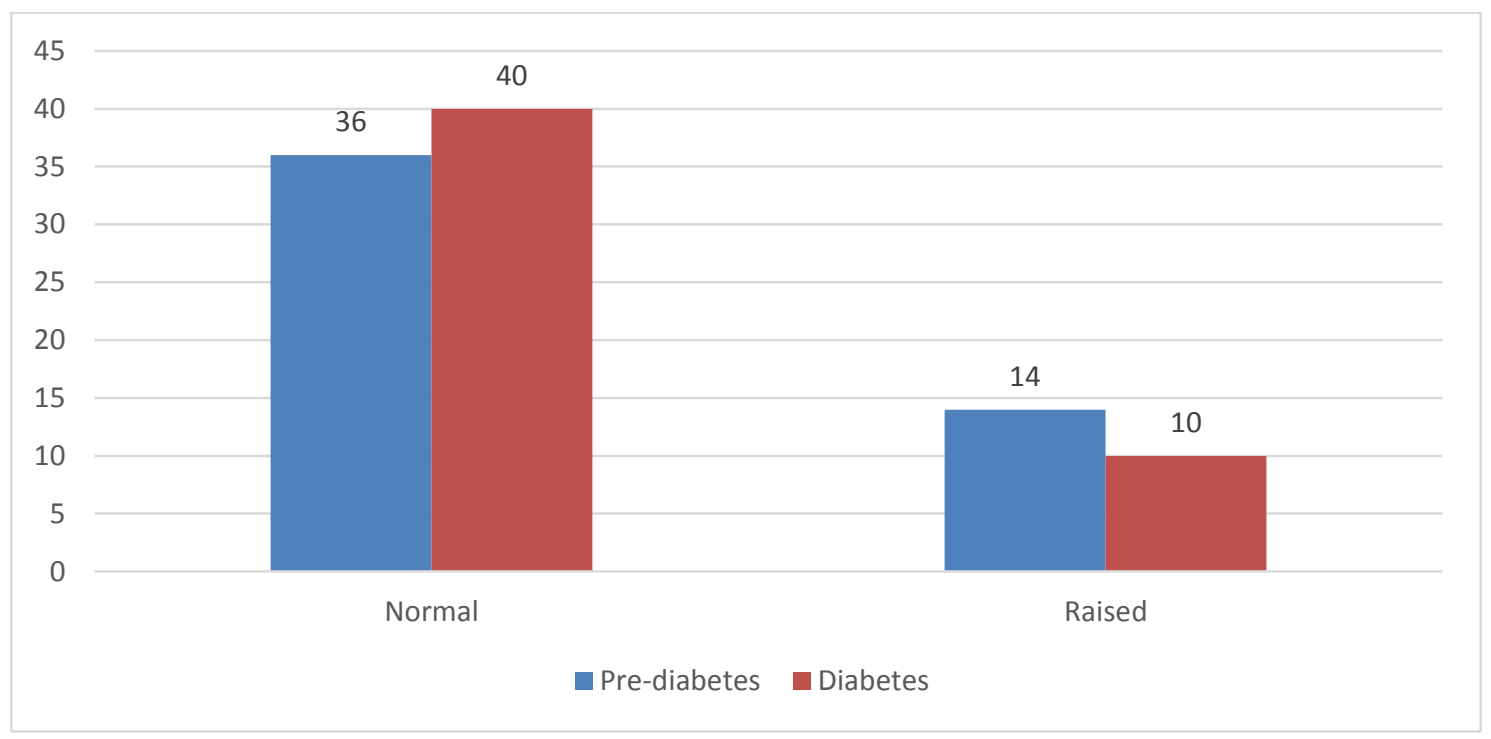

Figure 9: Bar diagram

Table 9: Relation of Uric acid with HbA1c for pre diabetics

\begin{tabular}{llll}
\hline & HbA1c $<6.4$ & HbA1c $>=6.4$ & P value \\
\hline Mean+-SD (Uric Acid) & $6.09+-1.4$ & $5.53+-0.68$ & 0.436 \\
\hline
\end{tabular}

The difference of mean uric acid wrt HbA1c was not significant, although people with lower HbA1c values had a higher uric acid levels 


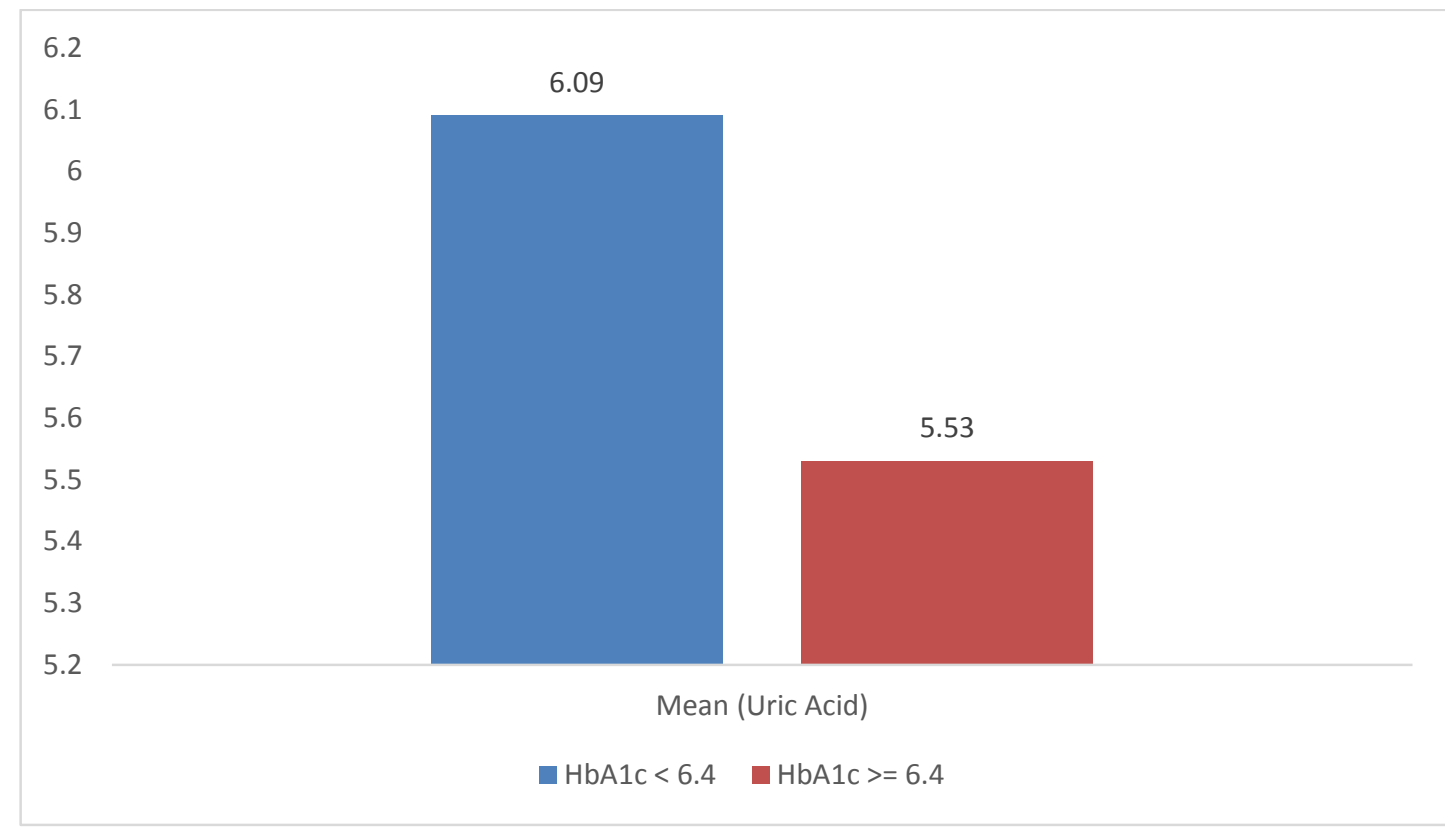

Figure 10: Bar Diagram

Table 10: Relation of Uric acid with FBS for pre diabetics

\begin{tabular}{llll}
\hline & FBS < 110 & FBS >= 110 & P value \\
\hline Mean +-SD (Uric Acid) & $5.98+-1.35$ & $6.24+-1.46$ & 0.571
\end{tabular}

The difference was not significant wrt uric acid levels with FBS values in prediabetics

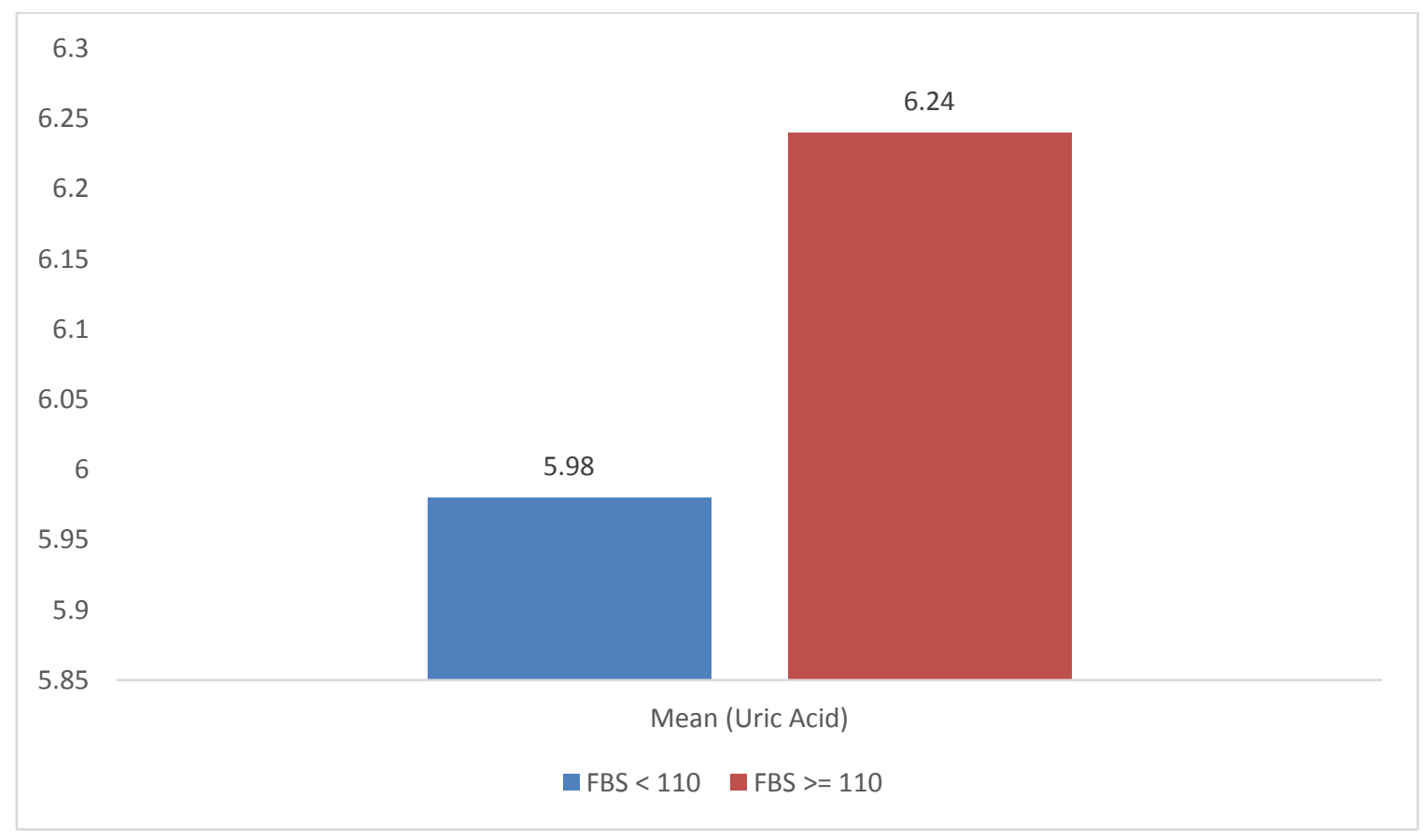

Figure 11: Bar Diagram

Table 11: Relation of Uric acid with PPBS for pre diabetics

\begin{tabular}{llll}
\hline & PPBS $<140$ & PPBS $>=140$ & P value \\
\hline Mean +-SD (Uric Acid) & $6.11+-1.46$ & $5.83+-0.99$ & 0.554
\end{tabular}

The difference was not significant, although people with lower PPBS had higher uric acid levels in prediabetics 


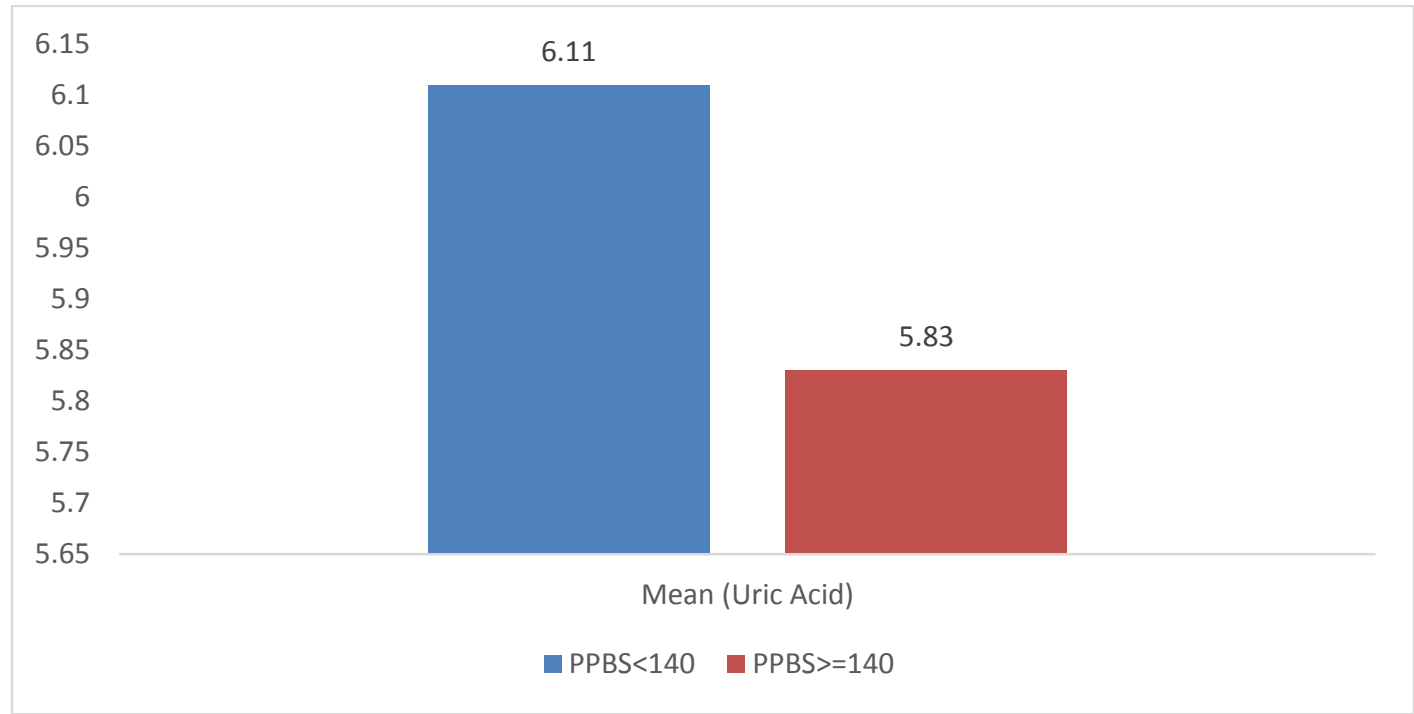

Figure 12: Bar Diagram

Table 12: Relation of Uric acid with HbA1c for diabetics

\begin{tabular}{llll}
\hline & HbA1c $<7$ & HbA1c >=7 & P value \\
\hline Mean+-SD(Uric Acid) & $6.67+-1.52$ & $5.31+-1.77$ & 0.038
\end{tabular}

There was a significant relation of lower uric acid mean values for people with elevated HbA1c over $7 \mathrm{~g} \%$ amongst diabetics

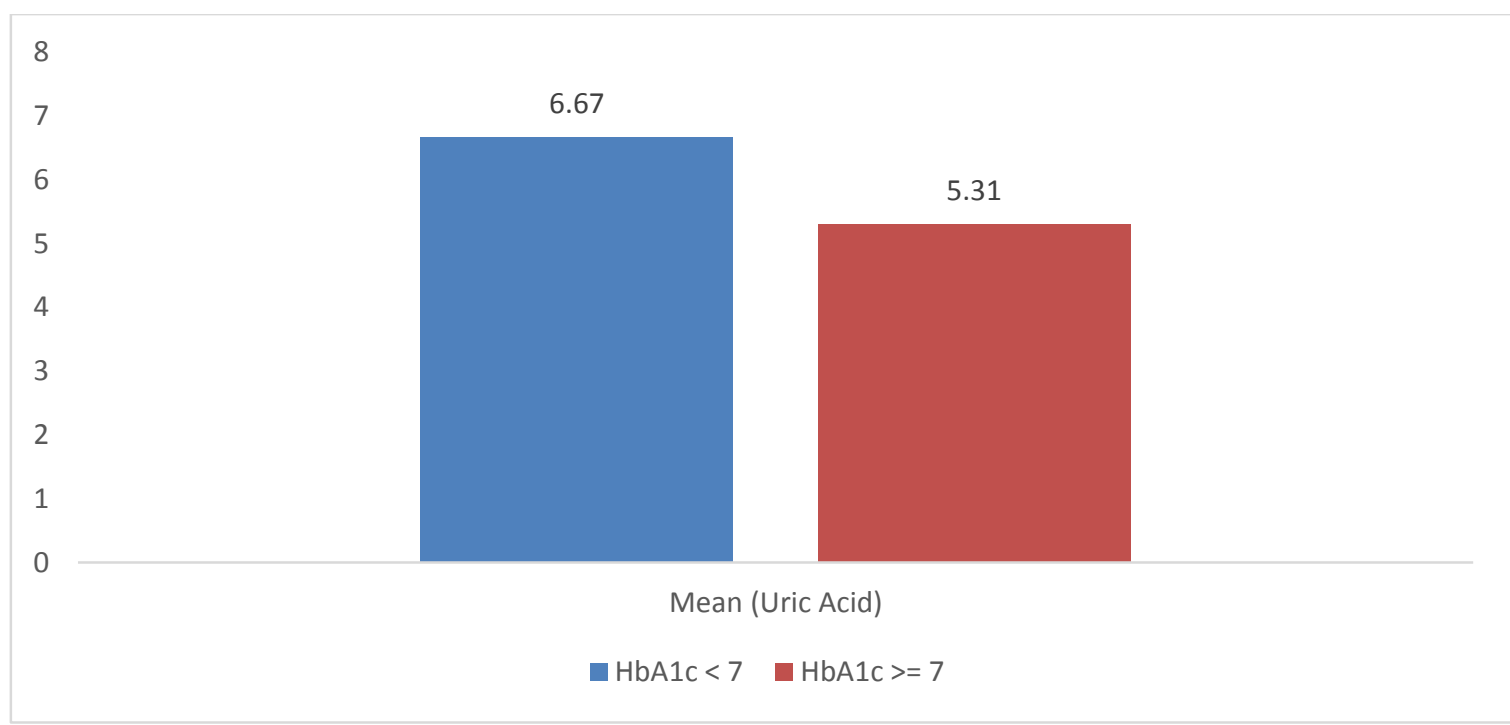

Figure 13: Bar Diagram

Table 13: Relation of Uric acid with FBS for diabetics

\begin{tabular}{llll}
\hline & FBS $<\mathbf{1 1 0}$ & FBS $>=110$ & P value \\
\hline Mean+-SD(Uric Acid) & $5.59+-1.77$ & $5.55+-1.81$ & 0.954
\end{tabular}

There was no significant relation, although mean uric acid levels were raised for people with FBS $<110$ amongst diabetics 


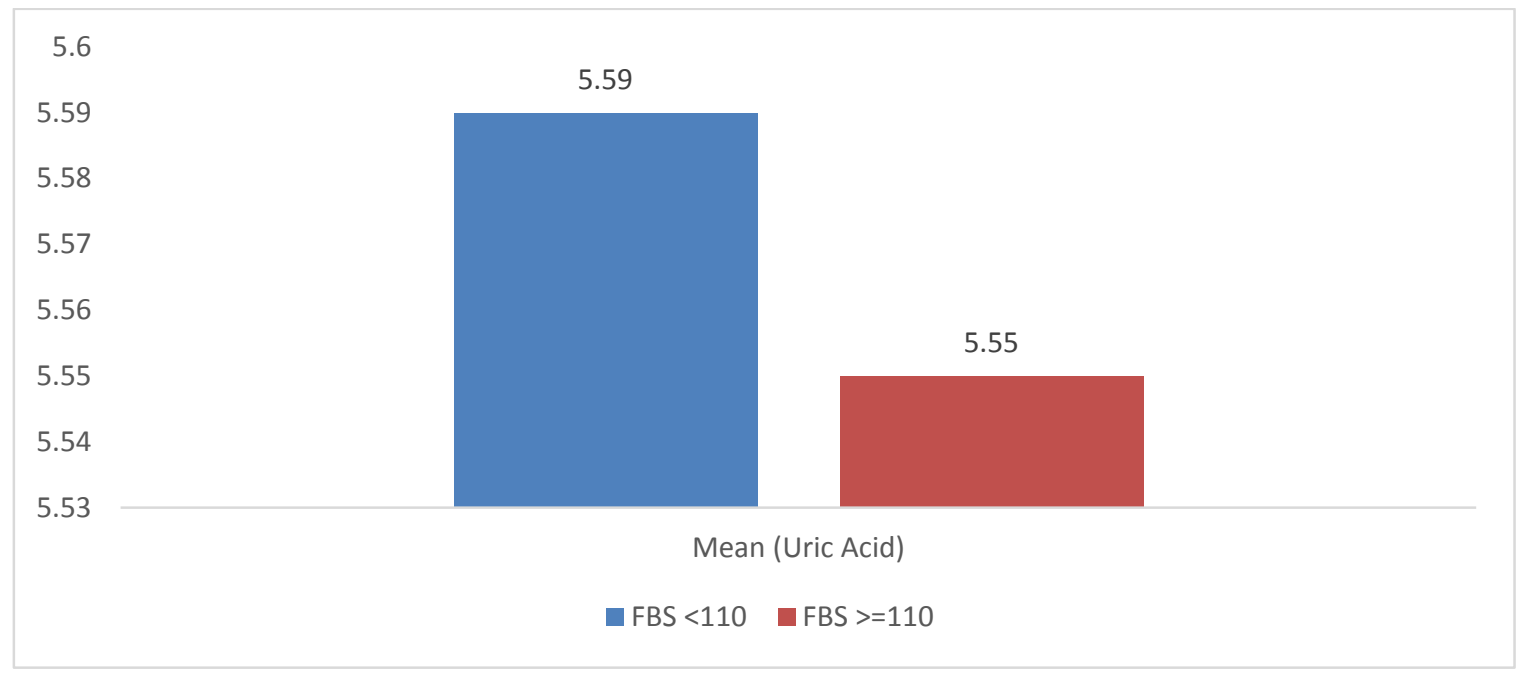

Figure 14: Bar Diagram

Table 14: Relation of Uric acid with PPBS for diabetics

PPBS $<140 \quad$ PPBS $>=140 \quad$ P value

Mean +-SD (Uric Acid) $\quad 5.68+-1.77 \quad 5.53+-1.81 \quad 0.83$

There was no significant relation but uric acid levels were higher in people with PPBS <140 amongst diabetics

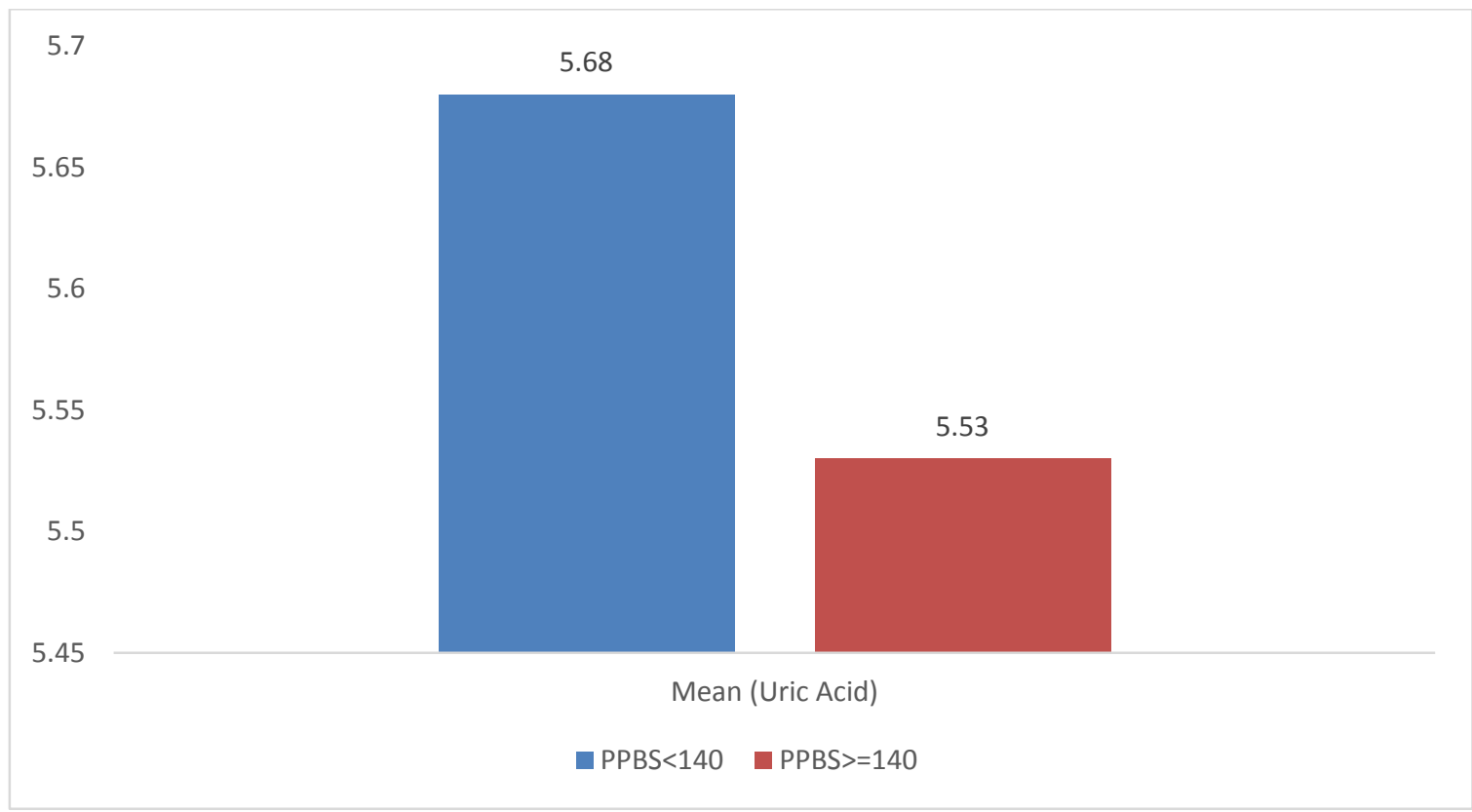

\section{Figure 15: Bar Diagram}

\section{DISCUSSION}

Uric acid usually has an antioxidative effect; however, uric acid becomes a strong oxidant in the environment of metabolic syndrome. ${ }^{52}$ This phenomenon of the urate redox shuttle may explain the paradoxical effects of uric acid on oxidative stress. Inflammation and oxidative stress induced by metabolic syndrome and hyperuricemia may predispose individuals to a higher risk for diabetes. This study was designed to see the relation of uric acid with glycemic levels in both diabetics and prediabetics. 
There was a significant relation between prediabetics who were younger in age compared to diabetics (almost a decade younger). The gender distribution was identical between the two groups. 53\% had complaint <1 year. $49 \%$ were on only OHAs, whereas $44 \%$ received both Insulin and OHAs. 7\% did not receive any medicines for diabetes prior to this study. 39\% had isolated HTN; $9 \%$ had IHD whereas $19 \%$ had both. 33\% did not have any comorbidity. There was a significant relation of FBS $<110$ in prediabetics compared to diabetics $>126$. There was a significant relation of PPBS $<140$ between prediabetics compared to diabetics $>200$. The diabetics had HbA1c significantly higher than prediabetics. Although proportionately more prediabetics had raised creatinine levels, but the difference was not significant. There was no relation between the groups wrt creatinine

The difference of mean uric acid wrt HbA1c was not significant, although people with lower HbA1c values had a higher uric acid levels. This correlated with the findings by Selvin E et al. ${ }^{32}$ Serum uric acid levels showed a similar bell-curved relation with fasting glucose levels. The baseline serum UA level has also been found to independently predict the $2 \mathrm{hPG}$ levels during 13.5 years follow-up in a Swedish male population, with a low regression coefficient of $0.01(\mathrm{p}=0.026) .{ }^{36}$

The difference was not significant wrt uric acid levels with FBS values in prediabetics. This correlated with the findings by Choi HK et al. ${ }^{15}$ In comparison, serum uric acid levels and frequency of hyperuricaemia monotonically increased with increasing fasting C-peptide levels, as with increasing serum insulin levels and insulin resistance. These associations were independent of other risk factors for hyperuricaemia such as age, sex, BMI, dietary factors, alcohol intake, renal function, hypertension and diuretic use. A cross-sectional study of 1877 Turkish men and women showed that those in the highest uric acid tertile had an odds ratio of 1.89 (95\% CI, 1.45-2.46) for a diagnosis of diabetes, compared with the lowest tertile. ${ }^{53}$ The difference was not significant, although people with lower PPBS had higher uric acid levels in prediabetics. This correlated with the findings by Chien et al. ${ }^{29} \mathrm{~A}$ biological mechanism underlying the bell-shaped relation between blood glucose levels and serum uric acid levels is thought to be due to the uricosuric effect of glycosuria, which occurs when the blood glucose level is greater than $\sim 10 \mathrm{mmol} / \mathrm{l}(180 \mathrm{mg} / \mathrm{dl})$. The positive association between uric acid concentration and diabetes may be explained by at least 3 potential mechanisms. First, metabolic syndrome, as a precursor of diabetes, induces high oxidative stress, which is worsened by the accompanying hyperuricemia.

There was a significant relation of lower uric acid mean values for people with elevated HbA1c over $7 \mathrm{~g} \%$ amongst diabetics. This correlated with the findings by Strasak et al. ${ }^{30}$ This level of blood glucose was consistent with that of $\mathrm{HbA} 1 \mathrm{c}$ that corresponded to the peak of serum uric acid in our data, further supporting this notion. Correspondingly, history of 
diabetes was significantly associated with lower levels of serum uric acid in this study as well as in previous studies. A recent study showed that hyperuricemia was associated with the severity of carotid plaque among Japanese men. ${ }^{49}$

There was no significant relation, although mean uric acid levels were raised for people with FBS $<110$ amongst diabetics. This correlated with the findings by Nan $\mathrm{H}$ et al. ${ }^{36}$ Their extended multivariate analyses showed that this inverse association became larger and stronger after adjusting for C-peptide, but became smaller and insignificant after adjusting for $\mathrm{HbA1c}$, suggesting that the inverse link was due to average blood glucose levels. Collectively, these results indicate that individuals with pre-diabetes may be at a higher risk of developing gout, but once they develop diabetes their risk may drop to a lower level than that of normal individuals. This potential impact on the eventual risk of gout was also supported by these results with hyperuricaemia as a dichotomous outcome using various definitions.

The mechanism behind these apparent gender differences remains unclear, although the role of female sex hormones has been suspected. A study among Chinese in Taiwan revealed that among non-diabetic subjects, FPG increased with increasing UA levels in women, but not in men. ${ }^{36}$

There was no significant relation but uric acid levels were higher in people with PPBS $<140$ amongst diabetics. A population-based cross-sectional study revealed that serum UA was strongly correlated with $2 \mathrm{hPG}$ in non-diabetic Mauritian men $(\mathrm{r}=0.15)$ and women $(\mathrm{r}=0.22)$ $(\mathrm{p}<0.001$ for both $) .{ }^{36}$

This study shows that there exists a relation between uric acid and inverse glycemic control, although due to small sample size, the relation was only proportional and not statistically significant. The implications are the recognition of a very inexpensive and readily available biochemical marker to target the treatment of diabetes and prediabetes, in clinically asymptomatic and occult cases. Starting early would be starting right, mitigating lots of complications and end organ damage, translating into saving of expenditure in health and economic impacts of the same. The study needs to be followed up by a multicentric larger sized study to identify closer relation between these two variables.

\section{CONCLUSION}

This study was performed in department of medicine, Saifee hospital Mumbai, where 50 patients each who were pre diabetics and diabetics were selected as per inclusion and exclusion criteria and the following findings were observed.

1. There was a significant relation between prediabetics who were younger in age compared to diabetics (almost a decade younger) 
2. The gender distribution was identical between the two groups

3. $53 \%$ had complaint $<1$ year

4. $49 \%$ were on only OHAs, whereas $44 \%$ received both Insulin and OHAs. $7 \%$ did not receive any medicines for diabetes prior to this study.

5. $39 \%$ had isolated HTN; $9 \%$ had IHD whereas $19 \%$ had both. $33 \%$ did not have any comorbidity.

6. There was a significant relation of FBS $<110$ in prediabetics compared to diabetics $>126$

7. There was a significant relation of PPBS $<140$ between prediabetics compared to diabetics $>200$

8. The diabetics had HbA1c significantly higher than prediabetics.

9. Although proportionately more prediabetics had raised creatinine levels, but the difference was not significant.

10. There was no relation between the groups wrt creatinine

11. The difference of mean uric acid wrt HbA1c was not significant, although people with lower HbA1c values had a higher uric acid levels

12. The difference was not significant wrt uric acid levels with FBS values in prediabetics

13. The difference was not significant, although people with lower PPBS had higher uric acid levels in prediabetics

14. There was a significant relation of lower uric acid mean values for people with elevated $\mathrm{HbA} 1 \mathrm{c}$ over $7 \mathrm{~g} \%$ amongst diabetics

15. There was no significant relation, although mean uric acid levels were raised for people with FBS $<110$ amongst diabetics

16. There was no significant relation but uric acid levels were higher in people with PPBS <140 amongst diabetics

\section{Recommendations}

1. Younger age in India is predisposed to prediabetes and diabetes

2. Often patients are silent, without symptoms and detected only by investigations, so investigations for prediabetes and diabetes should be mandatorily routine

3. Lower uric acid levels have correlation with impaired glycemic control and should be part of checkups for metabolic syndromes

4. Hypertension and heart disease commonly coexist with diabetes and should be tackled together

5. Uric acid monitoring should have a role in guiding glycemic goals

\section{Limitations}

1. Small sample size 
2. Single hospital based study

\section{REFERENCES}

1. Torres N, Avila-Nava A, Medina-Vera I, Tovar AR. Dietary Fiber and Diabetes. InScience and Technology of Fibers in Food Systems 2020 (pp. 201-218). Springer, Cham.

2. Derosa G, D'Angelo A, Maffioli P. Change of some oxidative stress parameters after supplementation with whey protein isolate in patients with type 2 diabetes. Nutrition. 2020 May 1; 73:110700.

3. Saproo N, Singh R. Study of serum magnesium levels in diabetes mellitus and its correlation with complications (retinopathy and HbA1C) a cross-sectional study of one year. Int. J. Adv. Med. 2017 Jan;4(1):263-9.

4. Verma S, Hussain ME. Obesity and diabetes: an update. Diabetes \& Metabolic Syndrome: Clinical Research \& Reviews. 2017 Jan 1;11(1):73-9.

5. Nanditha A, Ma RC, Ramachandran A, Snehalatha C, Chan JC, Chia KS, Shaw JE, Zimmet PZ. Diabetes in Asia and the Pacific: implications for the global epidemic. Diabetes care. 2016 Mar 1;39(3):472-85.

6. Hayashi Y, Yukita S. Rule extraction using Recursive-Rule extraction algorithm with J48graft combined with sampling selection techniques for the diagnosis of type 2 diabetes mellitus in the Pima Indian dataset. Informatics in Medicine Unlocked. 2016 Jan 1;2:92-104.

7. Laiteerapong N, Ham SA, Gao Y, Moffet HH, Liu JY, Huang ES, Karter AJ. The legacy effect in type 2 diabetes: impact of early glycemic control on future complications (the Diabetes \& Aging Study). Diabetes Care. 2019 Mar 1;42(3):41626.

8. Sharma A, Sharma R, Paul J, Tyagi A, Khari S, Prasad K. A study of microalbuminuria levels among patients with type 2 diabetic complications in Western UP. International Journal of Contemporary Medicine. 2017;5(1):84-9.

9. Asif M. Role of heavy metals in human health and particularly in respect to diabetic patients. TANG [HUMANITAS MEDICINEs. 2017 Feb 28;7(1):1-.

10. Bergman M, Manco M, Sesti G, Dankner R, Pareek M, Jagannathan R, Chetrit A, Abdul-Ghani M, Buysschaert M, Olsen MH, Nilsson PM. Petition to replace current OGTT criteria for diagnosing prediabetes with the 1-hour post-load plasma glucose $\geq$ $155 \mathrm{mg} / \mathrm{dl}$ (8.6 mmol/L). Diabetes research and clinical practice. 2018 Dec 1; 146:1833. 
11. Meena R, Meena S. Plasma Uric Acid Levels in Patients with Diabetes Mellitus and Impaired Glucose Tolerance Test in Comparison with Normal Subjects. International Journal of Science and Research. 2016;5(2):2090-3.

12. Talwar T, Tanwar L, Gupta M, Singal KK. Study of serum uric acid level in type 2 diabetes mellitus patients. Journal of Dental and Medical Sciences. 2017;16(10):839.

13. Roubenoff R, Klag MJ, Mead LA, Liang KY, Seidler AJ, Hochberg MC. Incidence and risk factors for gout in white men. Jama. 1991 Dec 4;266(21):3004-7.

14. Whitehead TP, Jungner I, Robinson D, Kolar W, Pearl A, Hale A. Serum urate, serum glucose and diabetes. Annals of clinical biochemistry. 1992 Mar;29(2):159-61.

15. Choi HK, Ford ES. Haemoglobin A1c, fasting glucose, serum C-peptide and insulin resistance in relation to serum uric acid levels - the Third National Health and Nutrition Examination Survey. Rheumatology. 2008 May 1;47(5):713-7.

16. Plan and operation of the third national health and nutrition examination survey, 1988-94, Vital Health Stat,1994, vol.32 (pg. 1-407)

17. US Department of Health and Human Services, National Center for Health Statistics. NHANES III reference manuals and reports (CD-ROM). Hyattsville, MD: Centers for Disease Control and Prevention. 1996 Oct.

18. Cook DG, Shaper AG, Thelle DS, Whitehead TP. Serum uric acid, serum glucose and diabetes: relationships in a population study. Postgraduate medical journal. 1986 Nov $1 ; 62(733): 1001-6$.

19. Dessein PH, Shipton EA, Stanwix AE, Joffe BI, Ramokgadi J. Beneficial effects of weight loss associated with moderate calorie/carbohydrate restriction, and increased proportional intake of protein and unsaturated fat on serum urate and lipoprotein levels in gout: a pilot study. Annals of the rheumatic diseases. $2000 \mathrm{Jul}$ 1;59(7):53943.

20. Emmerson B. Hyperlipidaemia in hyperuricaemia and gout. Annals of the rheumatic diseases. 1998 Sep 1;57(9):509-10.

21. Enomoto A, Kimura H, Chairoungdua A, Shigeta Y, Jutabha P, Cha SH, Hosoyamada M, Takeda M, Sekine T, Igarashi T, Matsuo H. Molecular identification of a renal urate-anion exchanger that regulates blood urate levels. Nature. 2002 May;417(6887):447-52.

22. Choi HK, Mount DB, Reginato AM. Pathogenesis of gout. Annals of internal medicine. 2005 Oct 4;143(7):499-516. 
23. Chou P, Lin KC, Lin HY, Tsai ST. Gender differences in the relationships of serum uric acid with fasting serum insulin and plasma glucose in patients without diabetes. The Journal of rheumatology. 2001 Mar 1;28(3):571-6.

24. Koenig W, Meisinger C. Uric acid, type 2 diabetes, and cardiovascular diseases: fueling the common soil hypothesis.

25. Strazzullo P, Puig JG. Uric acid and oxidative stress: relative impact on cardiovascular risk. Nutrition, Metabolism and Cardiovascular Diseases. 2007 Jul 1;17(6):409-14.

26. Strasak AM, Rapp K, Hilbe W, Oberaigner W, Ruttmann E, Concin H, Diem G, Pfeiffer KP, Ulmer H. The role of serum uric acid as an antioxidant protecting against cancer: prospective study in more than 28000 older Austrian women. Annals of Oncology. 2007 Nov 1;18(11):1893-7.

27. Cutler RG. Urate and ascorbate: their possible roles as antioxidants in determining longevity of mammalian species. Archives of gerontology and geriatrics. $1984 \mathrm{Dec}$ 1;3(4):321-48.

28. Dehghan A, Van Hoek M, Sijbrands EJ, Hofman A, Witteman JC. High serum uric acid as a novel risk factor for type 2 diabetes. Diabetes care. 2008 Feb 1;31(2):361-2.

29. Chien KL, Chen MF, Hsu HC, Chang WT, Su TC, Lee YT, Hu FB. Plasma uric acid and the risk of type 2 diabetes in a Chinese community. Clinical chemistry. 2008 Feb $1 ; 54(2): 310-6$.

30. Strasak A, Ruttmann E, Brant L, Kelleher C, Klenk J, Concin H, Diem G, Pfeiffer K, Ulmer H, VHM\&PP Study Group. Serum uric acid and risk of cardiovascular mortality: a prospective long-term study of 83683 Austrian men. Clinical chemistry. 2008 Feb 1;54(2):273-84.

31. Zhang X, Gregg EW, Williamson DF, Barker LE, Thomas W, Bullard KM, Imperatore G, Williams DE, Albright AL. A1C level and future risk of diabetes: a systematic review. Diabetes care. 2010 Jul 1;33(7):1665-73.

32. Selvin E, Steffes MW, Zhu H, Matsushita K, Wagenknecht L, Pankow J, Coresh J, Brancati FL. Glycated hemoglobin, diabetes, and cardiovascular risk in nondiabetic adults. New England Journal of Medicine. 2010 Mar 4;362(9):800-11.

33. American Diabetes Association. 5. Prevention or delay of type 2 diabetes. Diabetes Care. 2017 Jan 1;40(Supplement 1):S44-7.

34. Diabetes Prevention Program Research Group. HbA1c as a predictor of diabetes and as an outcome in the diabetes prevention program: a randomized clinical trial. Diabetes care. 2015 Jan 1;38(1):51-8. 
35. American Diabetes Association. Diagnosis and classification of diabetes mellitus. Diabetes care. 2013 Jan;36(Suppl 1):S67.

36. Nan H, Pang Z, Wang S, Gao W, Zhang L, Ren J, Ning F, Tuomilehto J, Qiao Q. Serum uric acid, plasma glucose and diabetes. Diabetes and Vascular Disease Research. 2010 Jan;7(1):40-6.

37. Chou P, Lin KC, Lin HY, Tsai ST. Gender differences in the relationships of serum uric acid with fasting serum insulin and plasma glucose in patients without diabetes. J Rheumatol 2001; 28: 571-576

38. Hodge AM, Boyko EJ, de Courten M, et al. Leptin and other components of the Metabolic Syndrome in Mauritius - a factor analysis. Int J Obes Relat Metab Disord 2001; 25: 126-131.

39. Ohlson LO, Larsson B, Bjorntorp P, et al. Risk factors for type 2 (non-insulindependent) diabetes mellitus. Thirteen and one-half years of follow-up of the participants in a study of Swedish men born in 1913. Diabetologia 1988; 31: 798805.

40. Schulze MB, Hu FB. Primary prevention of diabetes: what can be done and how much can be prevented?. Annu. Rev. Public Health. 2005 Apr 21; 26:445-67.

41. Lee YT, Sung FC, Lin RS, Hsu HC, Chien KL, Yang CY, Chen WJ. Peripheral blood cells among community residents living near nuclear power plants. Science of the total environment. $2001 \mathrm{Dec} 3 ; 280(1-3): 165-72$.

42. Onat A, Uyarel H, Hergenç G, Karabulut A, Albayrak S, Sarı I, Yazııı M, Keleş I. Serum uric acid is a determinant of metabolic syndrome in a population-based study. American journal of hypertension. 2006 Oct 1;19(10):1055-62.

43. Hansel B, Giral P, Nobecourt E, Chantepie S, Bruckert E, Chapman MJ, Kontush A. Metabolic syndrome is associated with elevated oxidative stress and dysfunctional dense high-density lipoprotein particles displaying impaired antioxidative activity. The Journal of Clinical Endocrinology \& Metabolism. 2004 Oct 1;89(10):4963-71.

44. Hayden MR, Tyagi SC. Uric acid: A new look at an old risk marker for cardiovascular disease, metabolic syndrome, and type 2 diabetes mellitus: The urate redox shuttle. Nutrition \& metabolism. 2004 Dec 1;1(1):10.

45. Patterson RA, Horsley ET, Leake DS. Prooxidant and antioxidant properties of human serum ultrafiltrates toward LDL important role of uric acid. Journal of Lipid Research. 2003 Mar 1;44(3):512-21.

46. Johnson RJ, Kang DH, Feig D, Kivlighn S, Kanellis J, Watanabe S, Tuttle KR, Rodriguez-Iturbe B, Herrera-Acosta J, Mazzali M. Is there a pathogenetic role for uric 
acid in hypertension and cardiovascular and renal disease?. Hypertension. 2003 Jun 1;41(6):1183-90.

47. Feig DI, Mazzali M, Kang DH, Nakagawa T, Price K, Kannelis J, Johnson RJ. Serum uric acid: a risk factor and a target for treatment?. Journal of the American Society of Nephrology. 2006 Apr 1;17(4 suppl 2):S69-73.

48. Mellen PB, Bleyer AJ, Erlinger TP, Evans GW, Nieto FJ, Wagenknecht LE, Wofford MR, Herrington DM. Serum uric acid predicts incident hypertension in a biethnic cohort: the atherosclerosis risk in communities study. Hypertension. 2006 Dec $1 ; 48(6): 1037-42$.

49. Ishizaka N, Ishizaka Y, Toda EI, Nagai R, Yamakado M. Association between serum uric acid, metabolic syndrome, and carotid atherosclerosis in Japanese individuals. Arteriosclerosis, thrombosis, and vascular biology. 2005 May 1;25(5):1038-44.

50. Quinones Galvan A, Natali A, Baldi SI, Frascerra SI, Sanna GI, Ciociaro DE, Ferrannini E. Effect of insulin on uric acid excretion in humans. American Journal of Physiology-Endocrinology And Metabolism. 1995 Jan 1;268(1):E1-5.

51. Bo S, Cavallo-Perin P, Gentile L, Repetti E, Pagano G. Hypouricemia and hyperuricemia in type 2 diabetes: two different phenotypes. European journal of clinical investigation. 2001 Apr;31(4):318-21.

52. Choromańska B, Myśliwiec P, Łuba M, Wojskowicz P, Myśliwiec H, Choromańska K, Żendzian-Piotrowska M, Dadan J, Zalewska A, Maciejczyk M. Impact of Weight Loss on the Total Antioxidant/Oxidant Potential in Patients with Morbid Obesity-A Longitudinal Study. Antioxidants. 2020 May;9(5):376.

53. Onat A, Uyarel H, Hergenç G, Karabulut A, Albayrak S, Sarı I, Yazıcı M, Keleş I. Serum uric acid is a determinant of metabolic syndrome in a population-based study. American journal of hypertension. 2006 Oct 1;19(10):1055-62.

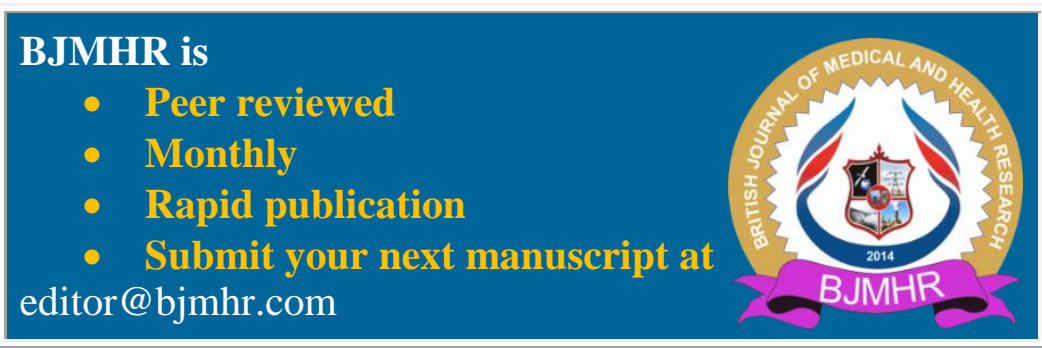

